\title{
OS DIREITOS DA PERSONALIDADE EM FACE DE UMA VISÃO MULTIDISCIPLINAR DO DIREITO: RESPONSABILIDADE CIVIL DO ESTADO E A DA INTEGRIDADE DO PRESO
}

Horácio MONTESCHIO ${ }^{1}$

Anisio MONTESCHIO JUNIOR ${ }^{2}$

ISSUE DOI: $10.21207 / 1983.4225 .1016$

\begin{abstract}
RESUMO
A responsabilização do Estado se evidencia diante de dois fundamentos distintos, sendo o primeiro deles consolidado na culpa administrativa, a qual é conceituada como sendo aquela que o Estado irá responder, se o dano tiver origem em um serviço estatal defeituoso, ou seja, se analisa o desempenho do serviço público prestado. O problema suscitado no presente trabalho reside na responsabilidade do Estado em face da preservação da integridade do preso. O método utilizado é o dedutivo, com a análise de decisões dos tribunais superiores pátrios, ao final apresentar as conclusões que convergem com a posição do jurisprudencial. Como temática relacionada a contribuição cientifica o presente trabalho
\end{abstract}

\footnotetext{
${ }^{1}$ Pós-Doutor em Direitos Humanos pelo Ius Gentium Conimbrigae da Faculdade de Direito da Universidade de Coimbra-Portugal. Pós Doutor pelo UNICURITIBA. Doutor em Direito pela FADISP. Mestre em Direitos da Personalidade pela UNICESUMAR. Professor de direito processual no curso de Graduação e mestrado da Universidade Paranaense. UNIPAR. Professo de Direito Processual Civil na Graduação UNICESUMAR. Currículo Lattes: http://lattes.cnpq.br/8861821320530256. Contato: h.monteschio@uol.com.br.

2 Doutorando em direito pela FADISP; Mestre em Direito pelo UNICESUMAR. Anisinho@wnet.com.br.
} 
busca consolidar e difundir nos meios acadêmicos a proteção dos direitos da personalidade e da integridade física do preso, com o objetivo de impedir que qualquer retrocesso a esses direitos seja proposto.

Palavras-chave: responsabilidade civil; integridade do preso; direito da personalidade; decisões tribunais superiores; vedação do retrocesso em matéria de direitos fundamentais.

\begin{abstract}
The State's accountability is evident in the face of two distinct fundamentals, the first of which is consolidated in administrative fault, which is conceptualized as the one that the State will respond to, if the damage originates from a defective state service, that is, it is analyzed performance of the public service provided. The problem raised in the present work lies in the State's responsibility towards preserving the prisoner's integrity. The method used is the deductive one, with the analysis of decisions of the superior national courts, at the end to present the conclusions that converge with the position of the jurisprudential. As a theme related to scientific contribution, the present work seeks to consolidate and disseminate in academic circles the protection of the rights of the prisoner's personality and physical integrity, with the objective of preventing any regression to these rights from being proposed.
\end{abstract}

Keywords: civil liability; prisoner integrity; personality right; higher court decisions; blocking backward fundamental rights.

\title{
INTRODUÇÃO
}

A responsabilização do Estado se evidencia diante de dois fundamentos distintos, sendo o primeiro deles consolidado na culpa administrativa, a qual é conceituada como sendo aquela que o Estado irá responder, se o dano tiver origem em um serviço estatal defeituoso, ou seja, se analisa o desempenho do serviço público prestado. O problema suscitado no presente trabalho reside na responsabilidade do Estado em face da preservação da integridade do preso.

Configura-se como sendo o segundo dos fundamentos a do risco administrativo, o Estado responderá objetivamente pelos danos que causar, independentemente de culpa.

Nos dias atuais, a fundamento adotado pelo Brasil reside na responsabilidade civil do Estado com fundamento no risco administrativo. Neste pensar cabe ao Estado responder objetivamente pelos danos que seus agentes causarem a terceiros, com base no art. $37, \S 6^{\circ}$ da Constituição Federal. Cabe destacar o fato de que excepcionalmente, reconhece-se a responsabilidade subjetiva do Estado, fundada na culpa administrativa.

A responsabilidade do Estado será objetiva em virtude da conduta comissiva do Estado e por exercício de uma atividade de risco. Por sua vez, a responsabilidade será subjetiva por conduta omissiva do Estado, por condutas omissivas ou comissivas de pessoas jurídicas de direito 
privado estatais exploradoras de atividade econômica, e quanto à responsabilidade civil do agente público.

A integridade física dos detentos é de responsabilidade do Estado, o qual deverá manter vigilância constante e eficiente, bem como tratamento adequado à saúde física e mental dos mesmos.

É inegável que o preso possui todas as proteções inerentes a preservação da sua personalidade, portanto, toda e qualquer violação a esses direitos representam uma afronta a esses direitos essenciais a todas as pessoas. Cabe ressaltar, que estando encarcerado o preso se encontra sob a responsabilidade do Estado, assim sendo, a fortiori deverá ter esses direitos ainda mais garantidos.

As decisões proferidas pelos tribunais pátrios, as quais vêm ao encontro da proteção desses direitos, razão pela qual a sua proteção deve ser evidenciada, explicitada e protegida a todo instante.

Cabe ressaltar que o presente trabalho abre a sua ponderação destacando a importância dos direitos da personalidade, avançando destacando a responsabilidade civil do Estado, consolidada no art. 37, $\S 6^{\circ}$ da Constituição Federal. Em momento seguinte serão analisadas as decisões dos Tribunais Superiores, especificamente decisão do Supremo Tribunal Federa e do Superior Tribunal de Justiça, para ao final elaborar as conclusões que estão em consonância com as referidas decisões.

\section{DOS DIREITOS DA PERSONALIDADE}

Ao compulsar os relatos históricos, encontramos que a tutela da personalidade já havia tutelada na hybris grega e na iniura romana. Existiam as distinções entre classe, mantidas pelos estatutos jurídicos, os quais estabeleciam, tão-somente, distinções quantitativas. Com o escopo de proteção ao bem comum, adotando as ideias de Aristóteles, passou-se a conceber a igualdade entre as pessoas, por conseguinte assume a noção de cláusula geral protetora da personalidade representada pela hybris.

Com todo o louvor a referência histórica do direito de personalidade aos gregos é atribuída aos Romanos a confecção da teoria jurídica da personalidade. Para o direito romano, personalidade estava circunscrita aos indivíduos que reunissem três status, a saber: o status libertatis, status civilitatis e o status familiae. 
Há que se observar que havia em Roma a tutela da personalidade humana a qual era disciplinada pela actio iniurarim, cujos contornos representavam uma cláusula geral de proteção aos direitos da personalidade do ser humano, a qual é descrita por Elimar Szaniawski:

\begin{abstract}
Todavia, esta proteção não apresentava, nem poderia oferecer uma tutela da pessoa na mesma intensidade e nos mesmos aspectos que hoje, principalmente devido à diferente organização social daquele povo, distante e desprendido da visão individualista que possuímos de nossa pessoa, à completa ausência de desenvolvimento as pesquisas médicas e biológicas que possuímos na atualidade e à inexistência de tecnologia e aparelhos que vissem a atacar e a violar as diversas manifestações da personalidade humana. ${ }^{3}$
\end{abstract}

A tutela da personalidade na Idade Média, com a queda do Império Romano sofreu alterações expressivas, notadamente na sociedade e na economia da Europa Ocidental. Para Tomás de Aquino entendia que a forma não era importante e sim a matéria, predominando a individualidade e a suprema dignidade do ser humano é a razão. Para Diogo Costa Gonçalves, acompanhando a doutrina tomista expressa a sua doutrina da seguinte forma:

Para a noção de natureza, reservava-se, assim a universalidade ou essência da realidade. Para a noção de pessoa, a realização própria, num sujeito determinado, dessa natureza ou realidade universal. Pessoa tornase, assim, a forma especial ou particular de ser de uma determinada natureza. ${ }^{4}$

Com isso a concepção cristã de pessoa como substancia racional, na imortalidade da alma e da ressurreição do corpo, ente com autonomia a qual precede a dignidade. Desta forma, na visão tomista, pessoa é a expressão de dignidade.

No século XII com o fortalecimento dos grandes latifundiários, proporcionado o enfraquecimento do feudalismo europeu, tornou-se visível que nestas porções de terras não encontrávamos o mesmo avanço dos costumes, tendo por fundamento vários fatores como questões políticas, econômicas e sociais.

\footnotetext{
${ }^{3}$ SZANIAWSKI, Elimar. Direitos de personalidade e sua tutela. São Paulo: Editora Revista dos Tribunais, 2005. p. 32.

${ }^{4}$ GONÇALVES, Diogo Costa. Pessoa e direitos da personalidade. Coimbra, 2008.p 26.
} 
Eventos como o humanismo no século XVI e o antropocentrismo forçaram os pensadores e filósofos a refletir o homem como ente que se relaciona entre si e cada um dentro de uma sociedade.

A proteção da pessoa humana, reconhecida pelo Estado, tem suas origens no liberalismo no final do século XVII, tendo como principal fomentadora a Grã Bretanha, com seu pensamento liberal a elaboração da Declaração da Colônia de Virginia em 1776.

Por sua vez, a França teve papel decisivo na elaboração da Declaração dos Direito do Homem, contando com os pensamentos de Rousseau, Montesquieu e Voltarie, servindo-se da revolução de 1789, onde acabou por instituir o Estado liberal com base no individualismo.

É um truísmo a ascensão do capitalismo dos séculos XVII e XVIII, com a extinção de privilégios da nobreza e o combate ao absolutismo. O iluminismo é uma marca deixada pelo século XVIII, destacando a adoção de liberdades, igualdades, propriedade privada, mercantilismo, tolerância, formatou a possibilidade de adoção de codificações para o direito civil.

Nos séculos XVII e XVIII, há um avanço com relação aos direitos de personalidade como um direito inerente a própria pessoa.

Sob a batuta de Gierke, Koehler e Huber, desenvolveu-se o direito de personalidade na Alemanha e Suíça, adotando, como dito acima, um único e genérico direito de personalidade.

Passa-se a uma nova visão sobre o direito da personalidade com a promulgação do Código Civil Alemão, o qual passa a representar um momento de grande instabilidade, na medida em que não previa em seu texto a cláusula geral de proteção à personalidade humana.

Em sentido contrário aos conceitos firmados na Alemanha trilhou a codificação Suíça, a qual inseriu em seu Código Civil, mais precisamente no artigo 28, de forma patente o direito geral da personalidade, passando a Suíça a figurar na vanguarda dos direitos da personalidade no início do século passado.

Avançando em nosso tema, condena-se o texto Constitucional de 1988 pelo fato de não consagrar uma cláusula geral de proteção aos direitos de personalidade a exemplo das constantes nas Constituições Italiana e Alemã.

Sobreleva enfatizar o fato de que os direitos de personalidade não devem receber classificações, ou mesmo ser fracionado em 


\title{
compartimentos estanques ou hermeticamente fechados. Neste sentido apresenta a doutrina Maria Celina Bodin de Moraes:
}

\begin{abstract}
Como já foi salientado em doutrina, a tutela da personalidade para ser eficaz, não pode ser fracionada em diversas fattispacie fechadas, como se fossem hipóteses autônomas não comunicáveis entre si. Tal tutela deve ser concebida de forma unitária, dado o seu fundamento, que é a unidade do valor da dignidade da pessoa. É facilmente constatável que a personalidade humana não se realiza através de um esquema fixo de situação jurídica subjetiva - o direito subjetivo -, mas sim por meio de uma complexidade de situações subjetivas que se podem apresentar ora como poder jurídico, ora como direito potestativo ou como autoridade parental, interesse legítimo, faculdade, estado; enfim, qualquer acontecimento ou circunstância (rectius, situação) juridicamente relevante. ${ }^{5}$
\end{abstract}

Ao analisar os recentes textos da doutrina pátria é visível a evolução dos conceitos, bem como o seu aprimoramento, na medida em que a dignidade da pessoa humana, esteja ela encarcerada ou não, está associada aos direitos da personalidade, para tanto cabe ressaltara doutrina de Daniel Eduardo Carnacchioni:

A dignidade da pessoa humana representa um direito geral da personalidade, base de todos os demais direitos relacionados direitos especiais, como honra, liberdade, nome, imagem, vida privada, intimidade entre outros. Essa cláusula geral é ponto de referência, o valor fundamental ser objeto de tutela do Estado e a base de inúmeras situações. ${ }^{6}$

\section{Ao tratar do tema dignidade da pessoa humana é imprescindível citar Ingo Wolfagang Sarlet:}

Não se pode olvidar, neste contexto, que a dignidade da pessoa humana, na sua condição de princípio fundamental e na sua relação com os direitos e deveres fundamentais (sem prejuízo de assumir, também nesta perspectiva, a condição de regra jurídica, impositiva ou proibitiva de determinadas condutas, por exemplo) possui uma dupla dimensão (jurídica) objetiva e subjetiva, que, por sua vez, pelo menos segundo a tradição jurídico-constitucional germânica, largamente difundida também entre nós, guarda relação com os valores fundamentais de uma determinada comunidade. Aliás, os princípios e direitos fundamentais são, neste sentido, expressão jurídico-constitucional (mediante a incorporação ao direito

\footnotetext{
${ }^{5}$ MORAES, Maria Celina Bodin de. Na medida da pessoa humana. Rio de Janeiro: Renovar, 2010. p. 126.

${ }^{6}$ CARNACCHIONI, Daniel Eduardo. Curso de direito civil. São Paulo: Editora Revista dos Tribunais, 2013.p. 195.
} 
positivo, na condição de direito objetivo) de uma determinada ordem de valores comunitária, não podendo ser reduzido a direito (posições subjetivas individuais).Também por esta razão (mas não exclusivamente é que a dignidade da pessoa, do indivíduo, é sempre a dignidade do individuo socialmente situação e responsável, implicando deveres fundamentais conexos e autônomos. $)^{7}$

\section{A importância do direito da personalidade, aliado aos direitos fundamentais, representam a tutela de proteção individual, precípua que deve ser ofertada a todos indistintamente, neste sentido leciona Pedro Pais de Vasconcelos:}

O fim que o direito subjectivo de personalidade visa proteger é a dignidade do seu titular, a sua dignidade enquanto pessoa, não uma pessoa em geral, nem um membro da humanidade, mas aquela pessoa única, individual e individuada, irrepetível e infungível. A dignidade humana é frequentemente agredida. Desde que há memória, é desrespeitada. A sua violação ocorre em contextos muito diferentes e de modo muito diversos. A sua defesa exige meios adequados à especificidade da lesão. Por ter de ser preventiva.

Se estiver consumada, já só poderá ser atenuada. ${ }^{8}$

Todavia, cabe aqui uma advertência, firmada por Gomes Canotilho, segundo a qual os direitos da personalidade não devem ser confundidos ou mesmo considerados sinônimos dos direitos fundamentais, senão vejamos:

Muitos dos direitos fundamentais são direitos de personalidade,
mas nem todos os direitos fundamentais são direitos de
personalidade. Os direitos de personalidade abarcam certamente os
direitos de estado (por ex: direito de cidadania), os direitos sobre a
própria pessoa (direito à vida, à integridade moral e física, direito à
privacidade), os direitos distintivos da personalidade (direito à
identidade pessoal, direito à informática) e muitos dos direitos de
liberdade (liberdade de expressão). Tradicionalmente, afastam-se
dos direitos de personalidade os direitos fundamentais políticos e
os direitos a prestações, por não serem atinentes ao ser como
pessoa. Contudo, hoje em dia, dada a interdependência entre o
estatuto positivo e negativo do cidadão, e em face da concepção de
um direito geral de personalidade como 'direito à pessoa ser e à
pessoa de vir', cada vez mais direitos fundamentais tendem a ser
direitos de personalidade e vice-versa (...) no entanto, não é apenas

${ }^{7}$ SARLET, Ingo Wolfgang. Dignidade da pessoa humana e direitos fundamentais na constituição federal de 1988. Porto Alegre: Livraria do Advogado Editora, 2012.p. 86.

${ }^{8}$ VASCONCELOS, Pedro Pais de. Direito de Personalidade. Coimbra: Almedina, 2006. p. 57. 
uma ordem de direito subjectivos, mas também uma ordem objectiva que justificará, entre outras coisas, o reconhecimento de direitos fundamentais a pessoas colectivas e organizações )ex.: os direitos reconhecidos às organizações de trabalhadores na Constituição Portuguesa). Neste domínio é particularmente visível a separação entre direitos fundamentais e direitos da personalidade. $^{9}$

A questão relacionada aos direitos fundamentais e direitos da personalidade cabe destacar a doutrina de Leonardo Estevam de Assis Zanini:

Daí, pode-se concluir que muitos dos direitos fundamentais são direito da personalidade, mas há direito que são enquadráveis apenas em uma das categorias, o que, no que toca ao conteúdo, demonstra apenas parcial coincidência. Ainda os direitos da personalidade são emanados sob o prisma das relações privadas, da proteção contra outros homens, enquanto que os direitos fundamentais são direitos públicos que objetivam a proteção do individuo contra ato do Estado. ${ }^{10}$

Cumpre destacar o fato de que os direitos fundamentais, com os direitos de personalidade não podem figurar, única e tão somente nos manuais e debates acadêmicos, pois a sua efetivação, a sua aplicação imediata, como descrito artigo $5^{\circ}, \S 1^{\circ}$ da Constituição Federal, neste sentido George Marmelstein formula seu posicionamento doutrinário:

Concretizar a norma constitucional nada mais é do que retirá-la do papel e trazê-la para o mundo real. É dar-lhe vida. Fazê-la gerar os efeitos nela previstos. Efetivá-la. Enfim, é conseguir que ela deixe de ser mero blá-bláblá constitucional para se transformar em um elemento concreto na sociedade. ${ }^{11}$

Por derradeiro, feitas as considerações históricas, bem como uma abordagem, ainda que de forma perfunctória sobre os direitos fundamentais e direitos da personalidade, os quais o aprofundamento devido renderia muitos outros aspectos e visões doutrinária. Todavia, em razão da presença desses direitos na Constituição Federal e no Código Civil brasileiro, demonstra o quão relevantes esses direitos no nosso sistema jurídico.

\footnotetext{
${ }^{9}$ CANOTILHO, José Joaquim Gomes. Direito constitucional e teoria da constituição. Coimbra: Almedina, 1999. p. 372.

${ }^{10}$ ZANINI, Leonardo Estevam de Assis. Direitos da personalidade. São Paulo; Saraiva, 2011. p. 62.

${ }^{11}$ MARMELSTEIN, George. Curso de direitos fundamentais. São Paulo: Atlas, 2013. p. 64.
} 


\section{DIREITOS DA PERSONALIDADE E DIREITOS HUMANOS}

A questão relacionada aos direitos humanos, por vezes é confundida e até mesmo encarada como sinônimo dos direitos da personalidade. A declaração dos Direitos do Homem de 1948, a qual não passou de mero instrumento de recomendações, mas sim uma forma específica de aplicação de defesa da pessoa humana e sua dignidade. Cabe citar Norberto Bobbio sobre o assunto:

Concepção individualista significa que antes vem o individuo, notem, o indivíduo isolado, que tem valor em si mesmo, e depois vem o Estado e não o contrário; que o Estado é feito pelo individuo e não o indivíduo pelo Estado; aliás, para citar o famoso artigo $2^{\circ}$, da Declaração de 89, a conservação dos direitos naturais e imprescritíveis do homem é objeto de qualquer associação política. [...] O caminho da paz e da liberdade certamente passa pelo reconhecimento e pela proteção dos direitos do homem, a começar pelo direito á liberdade de culto e de consciência, que foi o primeiro a ser proclamado durante as guerras religiosas que ensangüentaram a Europa durante um século, até os novos direitos (como o direito à privacidade e à tutela da própria imagem) que vão surgindo contra novas formas de opressão e desumanização tornadas possíveis pelo vertiginoso crescimento do poder manipulador do homem sobre si mesmo e sobre a natureza. ${ }^{11}$

A Declaração Universal dos Direitos Humanos é oriunda do pensamento de dignidade da pessoa humana formulado por Immanuel Kant. Em face a repulsa aos horrores históricos acontecidos durante a segunda Grande Guerra Mundial, assim lecionado por Nádia Araújo:

O início dessa nova vis directiva do campo dos valores (no plano internacional) alçando a proteção dos direitos humanos à condição de tema global da humanidade, surge a partir da urgência da comunidade internacional em dar uma resposta aos horrores ocorridos na Segunda Guerra, por causa da ruptura ocasionada pela ação do Estado totalitário. Para Hannah Arendt, essa ruptura do Estado totalitário com os demais criou um novo grupo de indivíduos no cenário internacional, os sem-direitos (rightless), pois, desprovidos de nacionalidade ou qualquer vínculo a um Estado nacional, perderam sua condição humana. Passaram a viver em um estágio de invisibilidade Diane dos demais setores, seja o Estado de sua proveniência, seja para aquele ao qual se dirigiam.

\footnotetext{
${ }^{11}$ BOBBIO, Noberto. Teoria geral da política: a filosofia política e as lições dos clássicos. org. de Michelangelo Bovero, tradução de Daniela BeccaciaVersiano. Rio de Janeiro: Campus, 2000. p. 480.
} 
As instituições internacionais deram-se conta da sua incapacidade de prover-lhes qualquer tipo de proteção. ${ }^{12}$

Sobreleva enfatizar o fato de que os instrumentos internacionais de proteção aos direitos humanos apresentam natureza subsidiária, pois se constituem em verdadeiros "soldados de reserva" em caso de falha nos sistemas nacionais.

Por outro lado, os direitos de personalidade, os quais já sofreram inúmeras críticas, divisões e classificações, entre as quais se destacam que não pode a pessoa ser ao mesmo tempo ser sujeito e objeto de direito; da amplitude da cláusula gera dos direitos de personalidade, tais argumentos são contestados por José Oliveira Ascensão ao argumento de que:

Do ponto de vista da construção técnica, faz depender a rejeição do direito geral de personalidade não tanto da sua impossibilidade lógica quanto do facto de tal construção ser desnecessária face à via alternativa do reconhecimento, em regime de números apertus, de direitos especiais de personalidade. ${ }^{13}$

Cumpre ressaltar o fato de que os direitos da personalidade assumem os contornos de categoria especial de direitos subjetivos. Importante contribuição ao presente trabalho é extraída da doutrina portuguesa de Guilherme Gonçalves Dray, segundo a qual:

\begin{abstract}
A matéria dos direitos de personalidade é central na sociedade contemporânea. A importância hoje reconhecida aos direitos de personalidade é, de forma clara, significativamente maior do que aquela que se atribuía aos direitos originários do Código de Seabra. Vários factores terão contribuído para a este reconhecimento acrescido: por um lado, por força do florescimento de alguns direitos de personalidade no próprio texto constitucional de 1976; em segundo lugar, porque a tutela conferida no Código Civil aos direitos de personalidade transcende, em larga escalar, o regime de (mera) responsabilidade civil constantes no artigo $2361 .^{\circ}$ Código de Seabra; em terceiro lugar, por força do recente e mencionado alastramento dos direito de personalidade a outras áreas e a alguns ramo de direito privado especial, nomeadamente ao Direito do Trabalho. Em quarto lugar, em virtude dos avanços doutrinários e jurisprudenciais que se registram a este nível. ${ }^{14}$
\end{abstract}

\footnotetext{
${ }^{12}$ ARAÚJO. Nádia de. Direito internacional privado. Rio de Janeiro: Renovar, 2008. p. 28.

${ }^{13}$ ASCENSÃO. José de Oliveira. Direito Civil. Teoria geral. Coimbra Editora: Coimbra, 1998. p. 79.

${ }^{14}$ DRAY, Guilherme Machado. Direitos de Personalidade. Coimbra: Almedina, 2006.p.6. ${ }^{16}$ VENOSA, Silvio de Salvo. Direito Civil: Parte geral. São Paulo Atlas, 2003.p. 150.
} 
Com estas considerações sucintas sobre os direitos humanos e os direitos da personalidade, é perfeitamente possível chegar à conclusão de que com a Emenda Constitucional 45/04 os laços jurídicos entre estes dois direitos tornaram-se ainda mais sólido e consistente.

\section{CONTEÚDO PATRIMONIAL DOS DIREITOS DA PERSONALIDADE}

Como conteúdo patrimonial dos direitos de personalidade deve ser entendido como aqueles que são inerentes à pessoa, inclusive a do preso, os quais não admitem avaliação pecuniária, sendo assim descritos na lição de Silvio de Salvo Venosa:

\footnotetext{
Diz-se que os direitos da personalidade são extrapatrimoniais porque inadmitem avaliação pecuniária, estando fora do patrimônio econômico. As indenizações que ataques a ele podem motivas, de índole moral, são substitutivos de um desconforto, mas não se equiparam à remuneração. Apenas no sentido metafórico e poético podemos afirmar que pertencem ao patrimônio moral de uma pessoa. São irrenunciáveis porque pertencem a própria vida, da qual se projeta a personalidade. ${ }^{16}$
}

E, razão da peculiaridade, bem como a sua correlação e congruência existentes entre o seu conteúdo, ainda que sucintamente, fazse necessário citá-los:

\subsection{DIREITO INATO}

São direitos que formam a essência da pessoa, são congênitos, inerentes a cada um, os quais não lhe são despojados em razão da sua prisão. Existem direitos que são adquiridos posteriormente ao nascimento.

Ao contrário do direito Grego ou Romano, fontes históricas que serviram de base ao presente trabalho, sendo que lá havia classificações de direitos da pessoa. Havia a figura do pai de família com poderes quase que totais sobre os seus familiares, bem como a concessão de privilégio ao primogênito na linha sucessória, mas não assistindo possibilidade de aquisição de bens hereditários aos demais integrantes da família. 
Por final, a feição de direito de personalidade como direito inato reveste-se de igual importância em face da sua necessidade, imprescindibilidade e generalidade, ou seja, não indispensáveis e concedidos a todos.

$\mathrm{Na}$ doutrina pátria, encontramos citações de que os direitos de personalidade são direitos inatos, cabendo ao Estado reconhecê-los, com os seguintes termos:

\begin{abstract}
Entendemos que os direitos da personalidade constituem direitos inatos - como a maioria dos escritores ora atesta - cabendo ao Estado apenas reconhecê-los e sancioná-los em um ou outro plano do direito positivo - a nível constitucional ou a nível de legislação ordinária - e dotando-os de proteção própria, conforme o tipo de relacionamento a que se volte, a saber: contra o arbítrio do poder público ou as incursões de particulares. ${ }^{15}$
\end{abstract}

Os direitos da personalidade, sendo inerente a pessoa, inclusive a do preso, é uma resposta ao Estado, o qual deve em primeiro momento existir e ser respeitado pelo segundo.

\title{
4.2 DIREITO VITALÍCIO
}

Os direitos de personalidade são inerentes a pessoa por toda a sua existência, como direitos inatos são necessários e são indissociáveis da pessoa por toda a sua existência, ou seja, permanecem inalterados em razão de situações que venha a limitar a liberdade física da pessoa, como no caso do preso.

Para Gilberto Haddad Jabur, o direito de personalidade caracteriza-se pela vitaliciedade, tendo em vista a essencialidade desses direitos e sua inafastabilidade do seu titular, com a seguinte doutrina:

\footnotetext{
Vitalícios, posto acompanham - justamente porque essências - a pessoa durante o curso de sua existência, sem embargo do exercício ad perpetuam de alguns de seus prolongamentos a cargo dos herdeiros do titular, autoriza referi-los como direitos privados subjetivos autônomos. ${ }^{16}$
}

\footnotetext{
${ }^{15}$ BITTAR, Carlos Alberto. Os direitos da personalidade. Rio de Janeiro: Forense Universitária, 1989. p. 7.

${ }^{16} \mathrm{JABUR}$, Gilberto Haddad. Liberdade de pensamento e direito à vida privada. São Paulo: Revista dos Tribunais, 2000.p. 87.
} 
A imagem, a honra os predicados pessoais intrínsecos e extrínsecos do ser humanos, tutelados pelos direitos de personalidade transcendem o caso concreto carnal e perpetuam-se para além da vida de seu titular. Inclusive, com a nova lei de abuso de autoridade, que vem a caracterizar o abuso a exposição da imagem do preso.

\subsection{DIREITO ABSOLUTO}

Em rápida e sucinta formulação: os direitos de personalidade são absolutos e oponíveis contra todos (erga omnes). Desta forma todos devem respeitar indistintamente os direitos de personalidade, bem como o seu titular pode exercê-lo contra todo e qualquer ataque que seja vítima.

O exemplo mais costumeiro reside no fato de sempre estarem em estado de colisão latente, os direitos de informação e os direitos de intimidade, razão pela qual sempre haverá uma prevalência de um sobre o outro, no caso concreto, sem que com isso venha a ocorrer uma ruptura na estrutura dos direitos de personalidade.

\subsection{DIREITO IMPRESCRITÍVEL}

Os direitos de personalidade são inatos, necessários e vitalícios. Por esta razão, mesmo que o seu titular não venha a utilizá-los, não se sirva deles não há como estabelecer um prazo para que o mesmo possa utilizálos, fruí-los pelo simples fato que são inerentes a pessoa, incluindo a pessoa do preso, não havendo prazo para seu aproveitamento.

Desta feita, é de fundamental importância o aspecto relacionado ao conteúdo patrimonial dos direitos da personalidade na medida em que só vem a corroborar a sua inerência a pessoa, a sua vinculação, mesmo após o término do ciclo vital, a sua possibilidade de oposição contra todos e não possibilidade de cessação da sua fruição, mesmo que não vem a exercê-los. 


\section{$5.1 \quad$ DIREITOS EXTRAPATRIMONIAIS}

Os direitos de personalidade são direitos extrapatrimoniais, pois seu objeto não possui valor econômico, não são mensuráveis, não podem ser objeto de penhora, comercialização e seu valor não é mensurável.

Para Enéas Costa Garcia os direitos da personalidade são indisponíveis, ou seja, o seu titular não pode os dispor "Em razão da especial natureza do bem jurídico tutelado, conjugado com o caráter extrapatrimonial, os direitos da personalidade são indisponíveis." ${ }^{17}$ Roxana Cardoso Brasileiro Borges, pondera pela possibilidade de relativização das expressões relacionadas aos direitos da personalidade, mas veja-se que a autora pondera em sua obra que tal direito é indisponível pelo seu titular, bem como ao Estado assiste o dever de preservá-lo:

A indisponibilidade dos direitos de personalidade, como uma das características desses direitos, será aqui questionada, diante das relativizações que a doutrina e a jurisprudência admitem, quando a diversas expressões da personalidade, assim como diante das experiências vivenciadas no cotidiano da vida brasileira. ${ }^{18}$

A questão relacionada à disponibilidade "o direito indisponível é aquele que está imune à vontade do titular quanto ao seu destinado, direito que não pode ser extinto ou modificado pela vontade." 19

Em relação à possibilidade de disposição dos direitos da personalidade se mostra o enunciado 4, aprovado na Jornada de Direito Civil promovida pelo Centro de Estudos Judiciários da Justiça Federal, no período de 11 a 13 de setembro de 2002, sob a coordenação do Min. Ruy Rosado de Aguiar, que se refere ao artigo 11 do Código Civil de 2002, com o seguinte teor: "O exercício dos direitos da personalidade pode sofrer limitação voluntária, desde que não seja permanente nem geral”.

\subsection{DIREITOS DA PERSONALIDADE E SUA RENÚNCIA POR PARTE DO TITULAR}

\footnotetext{
${ }^{17}$ GARCIA, Enéas Costa. Op. cit. p. 44.

18 BORGES, Roxana Cardoso Brasileiro. Disponibilidade dos direitos de personalidade e autonomia privada. São Paulo: Saraiva, 2005.p. 111.

${ }^{19}$ GARCIA, Enéas Costa. Direito geral da personalidade no sistema jurídico brasileiro. São Paulo: Editora Juarez de Oliveira, 2007.p. 46.
} 
Por tal predicado dos direitos da personalidade deve-se destacar que os mesmos são irrenunciáveis, para o professor Wanderlei de Paula Barreto os direitos da personalidade podem até não serem exercitados pelo seu titular, todavia, não há margem para possa renunciá-los.

O titular pode até mesmo não desfrutar ativamente certos direitos da personalidade, pode até mesmo, no âmbito da sua faculdade juridicamente reconhecida de agir ou não, deixar de buscar a tutela, em caso de ameaça ou lesão consumada a esses direitos. Não pode, contudo, de modo algum, renunciá-los, a priori, previamente abdicar, em caráter permanente e definitivo. Uma tal renúncia seria absolutamente nula, por afrontar normas de ordem pública (CC, art. $166, \mathrm{VII})^{20}$

Os direitos da personalidade são tão nobres em sua essência que mesmo havendo o interesse de seu titular em relativizá-lo, tal desiderato não é aceito pois trata-se de norma cogente que ao seu titular não assiste tal prerrogativa. Leonardo Galvani, formula sua doutrina neste sentido:

\begin{abstract}
Ora, uma vez que a pessoa carrega em si esses irrenunciáveis e inerentes direitos da personalidade, pode-se concluir que eles integram um conteúdo jurídico existencial, que variará de pessoa a pessoa, a ponto de formatar todas as suas situações subjetivas, patrimoniais e existenciais. Daí se entender a personalidade jurídica não apenas em face de relações patrimoniais, como originariamente é concebida pelo Estado liberal e cunhada desde 1916 até o século $\mathrm{XXI}^{23}$
\end{abstract}

Para Adriano de Cupis "Os direitos da personalidade não podem ser eliminados por vontade do seu titular - é o que costuma exprimir-se geralmente dizendo que os direitos da personalidade são irrenunciáveis." ${ }^{21}$

\title{
5.3 DIREITOS INDISPONÍVEIS
}

Pela própria razão de ser dos direitos de personalidade, como regra, estes assumem os contorne de indisponibilidade, pois são inatos, vitalícios.

\footnotetext{
${ }^{20}$ BARRETO, Wanderlei de Paula. Dos direitos da personalidade. In: ALVIM, Arruda; ALVIN, Tereza (coords.) comentários ao Código Civil brasileiro, parte geral. Rio de Janeiro: Forense, 2005.v. 1. p. 114. ${ }^{23}$ GALVANI, Leonardo. Personalidade jurídica da pessoa humana: uma visão do conceito de pessoa no Direito público e privado. Curitiba: Juruá, 2010.p. 68 e 69.

${ }^{21}$ CUPIS, Adriano de. Os direitos de personalidade. Lisboa: Livraria Morais Editora, 1961.p. 48.
} 
Pablo Stolze Gagliano e Rodolfo Pamplona Filho, assim expõe seu ponto de vista sobre a matéria:

Pelo fato de que ela abarca tanto a intransmissibilidade (impossibilidade de modificação subjetiva, gratuita ou onerosa inalienabilidade) quanto a irrenunciabilidade (impossibilidade de reconhecimento jurídico da manifestação volitiva de abandono do ${\text { direito })^{22}}^{22}$

Cabe ressaltar a regra contida no artigo 11 do Código Civil brasileiro, Lei 10.406 de 10 de janeiro de 2002, o qual possui a seguinte redação:

Art. 11. Com exceção dos casos previstos em lei, os direitos da personalidade são intransmissíveis e irrenunciáveis, não podendo o seu exercício sofrer limitação voluntária.

A intransmissibilidade nos ensinamentos de Adriano de Cupis: "Intransmissíveis. Nem o ordenamento jurídico pode consentir que o indivíduo se despoje daqueles direitos que por correspondentes aos bens mais elevados, tem o caracter de essencialidade". ${ }^{23}$

Maria Helena Diniz ensina que os Direitos da Personalidade são “(...) ilimitados, ante a impossibilidade de se imaginar um número fechado" 24 posto que tão subjetivos quanto a ideia de dignidade da pessoa humana, conferida a pessoa que se encontra encarcerada.

Isso posto, tanto os constitucionalizados, constantes dos incisos do Art. $5^{\circ}$, da Constituição Federal de 1988, quanto os elencados no Código Civil brasileiro de 2002, a maioria em seu Capítulo II, são rol exemplificativo, até mesmo porque muitos defendem a teoria pluralista, onde existiriam inúmeros Direitos da Personalidade tipificados na legislação, em oposição a teoria monista, não padecendo de uma inexorabilidade que poderia resultar na inadequada efetividade da busca pela plenitude da dignidade da pessoa humana.

\footnotetext{
${ }^{22}$ GAGLIANO, Pablo Stolze, PAMPLONA FILHO, Rodolfo. Novo curso de direito civil. São Paulo: Saraiva, 2002.p. 154.

${ }^{23}$ CUPIS, Adriano de. Op.cit, p. 52.

${ }^{24}$ DINIZ, Maria Helena.Curso de direito civil. v.1. Teoria Geral do Direito Civil. 28.ed. São Paulo: Saraiva, 2011. p. 135.
} 


\subsection{DIREITOS IRRENUNCIÁVEIS}

Não há como entender como uma pessoa possa renunciar a um direito inato.

Há relatos históricos da Idade Média, classificada como "morte civil" a qual pessoa renunciava a esta qualidade, assim descrito por Jefrey Richards: "A exclusão formal da sociedade privava o leproso de sues direitos civis. Ele se tornava uma não-pessoa, impossibilitada de legar ou herdar a propriedade, de defender suas demandas em tribunal, etc." ${ }^{25}$, veja, se era entendida como morte civil. Mas, não chega a ser uma renúncia, mas uma imposição, uma extinção da vida civil por vontade de terceiro, não por deliberação do titular.

Lapidar a posição legislativa que se extrai do Código Civil Português, cujo artigo 69 determina que "ninguém pode renunciar, no todo ou em parte, à sua capacidade jurídica. Portanto, Fernando Gonzaga Jayme enfrenta o assunto com a seguinte doutrina:

\footnotetext{
Não resta mais espaço, hodiernamente, para a perda (anda que voluntária) de direito da personalidade, que no extremo, levaria à perda da própria personalidade (morte civil). Se assim fosse, 'a privado absoluta da capacidade de a pessoa humana ser titular de direito e obrigações (em especial no concernente aos direitos de personalidade' transformaria o sujeito em objeto. ${ }^{26}$
}

De igual importância é extraída do Código Civil Peruano, de 1984, que em seu artigo $5^{\circ}$, estabelece de forma clara e precisa a irrenunciabilidade dos direitos fundamentais, assim descritos:

O Direito à vida, à integridade física, à liberdade e a honra e demais inerentes à pessoa humana são irrenunciáveis e não podem ser objeto de cessão. Seu exercício não pode sofrer limitação voluntária, salvo o disposto no artigo $6^{\circ}$.

Assim como há uma ressalva no artigo $6^{\circ}$ do Código Civil peruano, em nossa legislação existe a possibilidade de renúncia ao exercício de um direito de personalidade previsto no artigo 13 do código Civil, o qual dispõe:

\footnotetext{
${ }^{25}$ RICHARDS, Jefrey. Sexo, desvio e danação (sex, dissence and Damnation). Trad. Marco Antônio Esteves da Rocha \& Renato Aguiar. Rio de Janeiro; Jorge Zahar Editor, 1993.p. 159.

${ }^{26}$ JAYME, Fernando Gonzaga. Direitos humanos e sua efetivação pela corte interamericana de direitos humanos. Belo horizonte: Del Rey, 2005.p. 121.
} 
Salvo por exigência médica, é defeso o ato de disposição do próprio corpo, quando importar diminuição permanente da integridade física, ou contrariar os bons costumes.

Parágrafo único. $\mathrm{O}$ ato previsto neste artigo será admitido para fins de transplante, na forma estabelecida em lei especial.

\subsection{DIREITOS IMPENHORÁVEIS E INEXPROPRIÁVEIS}

Em razão do caráter indisponível, aos direitos da personalidade não assiste a possibilidade de sua alteração de titularidade. Como são inerentes a própria pessoa não é possível verificar a sua fruição por outro titular, a exceção contida no exercício pelos familiares do falecido em defesa de sua honra, imagem etc.

Podem ser classificados como bens fora do comércio, em razão da sua impossibilidade de transação, compensação e demais modalidade de transmissão admitidas em direito.

\section{RESPONSABILIDADE CIVIL DO ESTADO}

Com relação ao cenário referente a responsabilidade do Estado no que concerne a proteção do preso, cabe ressaltar que o entendido consolidado em virtude da evolução do pensamento jurídico sobre o tema no Brasil, consolidado no art. $37, \S 6^{\circ}$, da Constituição Federal:

\footnotetext{
Art. 37 - A administração pública direta e indireta de qualquer dos Poderes da União, dos Estados, do Distrito Federal e dos Municípios obedecerá aos princípios de legalidade, impessoalidade, moralidade, publicidade e eficiência e, também, ao seguinte: [...] $\S 6^{\circ}$ - As pessoas jurídicas de direito público e as de direito privado prestadoras de serviços públicos responderão pelos danos que seus agentes, nessa qualidade, causarem a terceiros, assegurado o direito de regresso contra o responsável nos casos de dolo ou culpa.
}

Desse dispositivo combinado com o entendimento majoritário da doutrina, extraímos que o Estado responde, objetivamente, sempre que demonstrada a existência de nexo de causalidade entre o dano/lesão e a atividade do agente em função do Estado. A discussão sobre possível culpa ou dolo só acontecerá, eventualmente, em um segundo momento, com 
relação a uma possível demanda regressiva por parte do Estado, contra o agente causador do dano. No entanto, a responsabilidade, em primeiro plano, é objetiva do Estado.

Assim é o entendimento adotado no Brasil, definida aqui nas palavras de Celso Antônio Bandeira de Mello, segundo o qual "A responsabilidade objetiva é a obrigação de indenizar que incumbe a alguém em razão de um procedimento licito ou ilícito que produziu uma lesão na esfera juridicamente protegida de outrem" 27

A abertura do estudo sob o prisma jurídico com relação à uma ação - no sentido de atitude - mal formulada por parte do Estado, nos permite fechar o raciocínio de que quando há uma conduta por meio de seu agente, bem como o dano e, para fechar as ligações, o nexo de causalidade, independente de culpa, a teoria adotada no Brasil pelo ordenamento vigente, doutrina majoritária confirmada pelos maiores tribunais de nosso país é a denominada responsabilidade civil do Estado.

Ocorre que o objeto do presente artigo busca a interpretação aprofundada nessa seara. A Constituição Federal de 1988 traz um arcabouço de direitos fundamentais e garantias sociais que devem ser aplicadas na nossa sociedade. Um dos mecanismos de aplicabilidade consiste na implantação das denominadas políticas públicas.

Ou seja, ações por parte do Estado devem ser tomadas em governos democráticos a fim de garantir aquilo que nossa Constituição tutela. A elaboração e consequente execução de políticas públicas é um dos mecanismos para alcançar esse objetivo. Existe uma obrigação estatal em promover e garantir aos cidadãos, com base em uma gama de princípios, medidas que concedam qualidade na proteção, preservação da saúde, educação, segurança, das pessoas que estão sob a sua custódia.

\subsection{TEORIA DO RISCO ADMINISTRATIVO}

A Constituição Federal adotou a teoria da responsabilidade objetiva do Poder Público, porém sobre a modalidade do risco administrativo, dessa maneira, a responsabilidade do estado pode ser

\footnotetext{
${ }^{27}$ BANDEIRA DE MELLO, Celso Antônio. Curso de Direito Administrativo. São Paulo: Malheiros, 2009. p. 325.
} 
atenuada, provando a culpa parcial e concorrente da vitima, e até mesmo excluída, provada a culpa exclusiva da vitima.

Conforme Sergio Cavalieri Filho "essa teoria surge como expressão concreta do princípio da igualdade dos indivíduos diante dos encargos públicos. É a forma democrática de repartir os ônus ou encargos sociais por todos aqueles que são beneficiados pela atividade da administração pública."28 Toda lesão sofrida pelo particular deve ser ressarcida, independentemente de culpa do agente público que a causou. $\mathrm{O}$ que se tem que verificar é, apenas, a relação de causalidade entre a ação administrativa e o dano sofrido pelo administrado.

O Min. Celso de Mello expôs seu posicionamento no seguinte voto:

A teoria do risco administrativo, consagrada em sucessivos documentos constitucionais brasileiros desde a Carta Política de 1946, confere fundamento doutrinário à responsabilidade civil objetiva do Poder Público pelos danos a que os agentes públicos, houverem dado causa, por ação ou omissão. Essa concepção teórica, que informa o princípio constitucional de responsabilidade civil objetiva do Poder Público, faz emergir, da mera ocorrência do ato lesivo causado à vítima pelo Estado o dever de indenizála pelo dano pessoal e/ou patrimonial sofrido, independentemente de caracterização de culpa dos agentes estatais ou de demonstração de falta do serviço público. (...) As circunstâncias do presente caso apoiadas em pressupostos fáticos soberanamente reconhecidos pelo Tribunal a quo - evidenciam que o nexo de causalidade material restou plenamente configurado em face do comportamento omissivo em que incidiu o agente do Poder Público (funcionário escolar), que se absteve de adotar as providências reparatórias que a situação estava a exigir. ${ }^{29}$

Para Hely Lopes Meirelles "o risco administrativo não significa que a indenização sempre será devida, pois não foi adotada a teoria do risco integral, e se a culpabilidade da vitima está reconhecida, afasta a ilicitude do fato. É que enquanto não evidenciar a culpabilidade da vitima, subsiste a responsabilidade objetiva da Administração." ${ }^{30}$

Se total a culpa da vitima, fica excluída a responsabilidade da Fazenda Pública. Existe uma certa confusão na doutrina a respeito da teoria do risco integral e a do risco administrativo. Essa confusão é mais de ordem

\footnotetext{
${ }^{28}$ CAVALIERI FILHO, Sérgio. Programa de responsabilidade civil. 9. Ed. São Paulo: Atlas, 2010. p. 234.

${ }^{29}$ RE 109615, 1. ${ }^{\text {a }}$ T., j. 28.05.1996, rel. Min. Celso de Mello, DJ 02.08.1996.

${ }^{30}$ MEIRELLES, Hely Lopes. Direito administrativo brasileiro. 33. ed. São Paulo: Malheiros, 2007. p. 601-602.
} 
semântica, pois todos partilham do entendimento de que as regras constitucionais impuseram a responsabilidade objetiva do Estado pela reparação do dano, e essa responsabilidade subsiste em qualquer circunstância, mas podendo ser excluída em caso de culpa da vítima ou de força maior.

A teoria do risco integral é a que mais se identifica com a responsabilidade objetiva adotada pela Constituição Federal, de acordo com os princípios da igualdade dos ônus e encargos sociais, na realidade estão atribuindo ao dispositivo constitucional os mesmos efeitos atribuídos aos que afirmam a adoção da teoria do risco administrativo.

$\mathrm{O}$ direito positivo brasileiro consagra a teoria do risco integral ou risco administrativo, identificando as duas teorias e explicando que o Estado responde sempre perante a vitima, independente de culpa do servidor, respondendo este perante o Estado e provando que procedeu culposa ou dolosamente. Não significa que o Estado é responsável por qualquer circunstancia, pois aplica as excludentes de responsabilidade.

\section{DECISÕES DOS TRIBUNAIS SUPERIORES}

O Supremo Tribunal Federal (STF) na ocasião do julgamento do ARE 700927, com relatoria do Ministro Gilmar Mendes, assumiu o entendimento de que no exato momento em que momento em que o individuo é preso, este é posto sob a guarda, proteção e vigilância das autoridades policiais, que têm por dever legal tomar todas as medidas que garantam a incolumidade física do detido, com base no art. $5^{\circ}$, inciso XLIX da Constituição Federal, quer por ato do próprio preso (ex. suicídio), quer por ato de terceiro. Destarte, a título de esclarecer o presente trabalho citar trechos do acordão proferido pelo Supremo Tribunal Federal:

Como já consignado pela decisão ora agravada, o Estado tem o dever objetivo de zelar pela integridade física e moral do preso sob sua custódia, atraindo, então, a responsabilidade civil objetiva, em razão de sua conduta omissiva, motivo pelo qual é devida a indenização decorrente da morte do detento, ainda que em caso de suicídio. Nesse sentido: "AGRAVO REGIMENTAL EM AGRAVO DE INSTRUMENTO. CONSTITUCIONAL E ADMINISTRATIVO. MORTE DE PRESO SOB CUSTÓDIA DO ESTADO. RESPONSABILIDADE DO ESTADO. AGRAVO IMPROVIDO. 
I- O Tribunal possui o entendimento de que o Estado se responsabiliza pela integridade física do preso sob a sua custódia, devendo reparar eventuais danos. Precedentes. II. Para se chegar à conclusão contrária à adotada pelo acórdão recorrido quanto à existência de nexo causal entre a omissão do Estado e o resultado morte, necessário seria o reexame do conjunto fático-probatório constante dos autos, o que atrai a incidência da Súmula 279 do STF. III - Agravo regimental improvido" (AI-AgR 799.789, Primeira Turma, Rel. Min. Ricardo Lewandowski, DJe de $1^{\circ} .2 .2011$ ). "RECURSO EXTRAORDINÁRIO. CONSTITUCIONAL. RESPONSABILIDADE CIVIL DO ESTADO. MORTE DE PRESO SOB CUSTÓDIA DO ESTADO. CONDUTA OMISSIVA. RESPONSABILIDADE OBJETIVA. AGRAVO REGIMENTAL AO QUAL SE NEGA PROVIMENTO” (RE AgR 594.902/DF, Primeira Turma, Rel. Min. Cármen Lúcia, DJe2.12.10). “(...) Nesse desiderato, cabe enfatizar, que é dever do Estado zelar pela integridade física dos detentos, conforme dispõe a Constituição Federal de 88, Título II DOS DIREITOS E GARANTIAS CONSTITUCIONAIS, art. $5^{\circ}$, inciso XLIX, afigurando-se, portanto, fora de dúvida, que a integridade física dos detentos é responsabilidade do Estado, que, para tanto, deve manter vigilância constante e eficiente, além de tratamento adequado à saúde física e mental dos mesmos. Assim, tem-se que configura culpa in vigilando do Estado, o fato da Delegacia de Polícia - como de qualquer estabelecimento prisional descurar-se dos cuidados necessários à preservação da incolumidade física dos presos, permitindo que fatalidades tal como a verificada, no caso vertente, aconteçam" (Trecho decisão monocrática do RE 566.040, Rel. Min. Ayres Britto, DJe 5.12.2011). "Agravo regimental em recurso extraordinário. 2. Morte de preso no interior de estabelecimento prisional. 3. Indenização por danos morais e materiais. Cabimento. 4. Responsabilidade objetiva do Estado. Art. 37, $\$ 6^{\circ}$, da Constituição Federal. Teoria do risco administrativo. Missão do Estado de zelar pela integridade física do preso. 5. Agravo regimental a que se nega provimento" (RE-AgR 418.566/PB, Segunda Turma, de minha relatoria, DJe 28.3.2008).

A Corte firmou o entendimento de que o Estado tem o dever objetivo de zelar pela integridade física e moral do preso sob sua custódia, atraindo então a responsabilidade civil objetiva, em razão de sua conduta omissiva, motivo pelo qual é devida a indenização decorrente da morte do detento, ainda que em caso de suicídio.

$\mathrm{Na}$ mesma linha de responsabilidade do Estado, o Superior Tribunal de Justiça no julgamento do AgRg no REsp 1.305.259, com relatoria do Min. Mauro Campbell Marques:

DIREITO ADMINISTRATIVO. RESPONSABILIDADE OBJETIVA DO ESTADO NO CASO DE SUICÍDIO DE DETENTO. A Administração Pública está obrigada ao pagamento de pensão e indenização por danos morais no caso de morte por 
suicídio de detento ocorrido dentro de estabelecimento prisional mantido pelo Estado. Nessas hipóteses, não é necessário perquirir eventual culpa da Administração Pública. Na verdade, a responsabilidade civil estatal pela integridade dos presidiários é objetiva em face dos riscos inerentes ao meio no qual foram inseridos pelo próprio Estado. Assim, devem ser reconhecidos os referidos direitos em consideração ao disposto nos arts. 927, parágrafo único, e 948, II, do CC.

Destarte, em consonância com o decido pelo Supremo Tribunal Federal, o Superior Tribunal de Justiça no julgado acima referido, proferido em 02/04/13 acabou por decidir que a administração pública está obrigada ao pagamento de pensão e indenização por danos morais no caso de morte por suicídio de detento ocorrido dentro de estabelecimento prisional mantido pelo Estado. Nessa oportunidade, entendeu que não seria necessário perquirir a culpa da administração pública, ou seja, que a responsabilidade estatal pela integridade dos presidiários é objetiva.

\section{CONCLUSÕES}

Por todo exposto, fica claro que o Estado deve ser responsabilizado, de forma objetiva, pelos danos ocorridos a integridade física e moral dos presos. Isso porque, o Estado tem o dever específico, previsto constitucionalmente, de assegurar a incolumidade física e moral de todos aqueles submetidos ao sistema carcerário.

Aliado ao desenvolvimento e consolidação, há que se ter em mente que mesmo direitos como os da personalidade não são absolutos, bem como seu exercício não é ilimitado, mesmo sendo inerente a pessoa e sua perpetuação deve ser sempre vista como avanço de nossa espécie humana. Mesmo nos casos concretos citados neste trabalho, a tônica que dos mesmos vem impregnada reside no fato de que não há como o titular do direito de personalidade transigir sobre este direito tão nobre e essencial a espécie humana. A autoridade pública deve velar para que estes direitos de personalidade sejam sempre preservados, inclusive no que concerne ao preso, mesmo com a recalcitrância de seu titular em não destacálo.

Também é importante salientar que a responsabilidade objetiva no Brasil admite excludentes de responsabilidade. Dessa forma, é possível concluir que não adotamos, como regra, a teoria do risco integral (que não admite excludentes de responsabilidade em nenhuma hipótese). Sendo assim, a responsabilidade estatal ficará excluída, se o Estado demonstrar a: 
(1) presença de motivo de força maior; (2) culpa exclusiva de terceiro; (3) culpa exclusiva da vítima.

Dessa forma, o Estado deverá ser responsabilizado por não garantir as condições necessárias para o cumprimento da pena. A responsabilidade civil do poder público é por ação, e não por omissão. Afinal, o Estado ciente das péssimas condições de detenção, envia pessoas a cárceres superlotados e insalubres.

\section{REFERÊNCIAS BIBLIOGRÁFICAS}

ARAÚJO. Nádia de. Direito internacional privado. Rio de Janeiro: Renovar, 2008.

ASCENSÃO. José de Oliveira. O direito introdução e teoria geral. Lisboa: Fundação calouste Gulbenkian, 1978.

BARRETO, Wanderlei de Paula. Dos direitos da personalidade. In: ALVIM, Arruda; ALVIN, Tereza (coords.) Comentários ao código civil brasileiro, parte geral. Rio de Janeiro: Forense, 2005.

BELTRÃO, Silvio Romero. Direitos da personalidade. São Paulo: Atlas, 2005.

BITTAR, Carlos Alberto. Os direitos da personalidade. Rio deJaneiro: Forense Universitária, 1989.

BOBBIO, Noberto. Teoria geral da política: a filosofia política e as lições dos clássicos. org. de Michelangelo Bovero, tradução de Daniela Beccacia Versiano. Rio de Janeiro: Campus, 2000.

BORGES, Roxana Cardoso Brasileiro. Disponibilidade dos direitos de personalidade e autonomia privada. São Paulo: Saraiva, 2005.

BRASIL. Supremo Tribunal Federal. Disponível em:

http://www.stf.jus.br/portal/cms/verNoticiaDetalhe.asp?idConteudo=290987. Acesso em: 20 de novembro de 2019.

BRASIL. Supremo Tribunal Federal. Disponível em:

http://www.stf.jus.br/portal/cms/verNoticiaDetalhe.asp?idConteudo=299385. Acesso em: 20 de novembro de 2019.

BRASIL. Supremo Tribunal Federal. Disponível em:

http://www.stf.jus.br/portal/cms/verNoticiaDetalhe.asp?idConteudo=313198. Acesso em: $20 \mathrm{de}$ novembro de 2019.

BRASIL. Disponível em < http://www.portaljustica.com.br/acordao/303759. Acesso em: 20 de novembro de 2019. 
BRASIL. Supremo Tribunal Federal. Disponível em: https://stf.jusbrasil.com.br/jurisprudencia/22059736/recurso-extraordinario-comagravo-are-700927go-stf. Acesso em: 20 de novembro de 2019.

CANOTILHO, José Joaquim Gomes. Direito constitucional e teoria da constituição. Coimbra: Almedina, 1999.

CARNACCHIONI, Daniel Eduardo. Curso de direito civil. São Paulo: Editora Revista dos Tribunais, 2013.

CUPIS, Adriano de. Os direitos de personalidade. Lisboa: Livraria Morais Editora, 1961.

DINIZ, Maria Helena.Curso de direito civil. v.1. teoriageral do direito civil. 28.ed. São Paulo: Saraiva, 2011.

DRAY, Guilherme Machado. Direitos de Personalidade. Coimbra: Almedina. 2006.

GAGLIANO, Pablo Stolze, PAMPLONA FILHO, Rodolfo. Novo curso de direito civil. São Paulo: Saraiva, 2002.

GALVANI, Leonardo. Personalidade jurídica da pessoa humana:uma visão do conceito de pessoa no Direito público e privado. Curitiba: Juruá, 2010.p. 68 e 69.

GARCIA, Enéas Costa. Direito geral da personalidade no sistema jurídico brasileiro. São Paulo: Editora Juarez de Oliveira, 2007.

GONÇALVES, Diogo Costa. Pessoa e direitos da personalidade. Coimbra: Almedina, 2008.

JABUR, Gilberto Haddad. Liberdade de pensamento e direito à vida privada. São Paulo: Revista dos Tribunais, 2000.

JAYME, Fernando Gonzaga. Direitos humanos e sua efetivação pela corte interamericana de direitos humanos. Belo horizonte: Del Rey, 2005.

MARMELSTEIN, George. Curso de direitos fundamentais. São Paulo: Atlas, 2013.

MORAES, Maria Celina Bodin de. Na medida da pessoa humana. Rio de Janeiro: Renovar, 2010.

PIOVESAN, Flávia. Direitos humanos e direito constitucional internacional. São Paulo: Saraiva, 2012.

RAMOS, André de Carvalho. Processo internacional de direitos humanos. Rio de Janeiro:

Renovar, 2002.

RICHARDS, Jefrey. Sexo, desvio e danação (sex, dissence and Damnation). Trad. Marco Antônio Esteves da Rocha \& Renato Aguiar. Rio de Janeiro: Jorge Zahar Editor, 1993.

SARLET, Ingo Wolfgang. Dignidade da pessoa humana e direitos fundamentais na constituição federal de 1988. Porto Alegre: Livraria do Advogado Editora, 2012. 
SZANIAWSKI, Elimar. Direitos de personalidade e sua tutela. São Paulo: Editora Revista dos Tribunais, 2005.

VASCONCELOS, Pedro Pais de. Direito de Personalidade. Coimbra: Almedina, 2006.

VENOSA, Silvio de Salvo. Direito civil: parte geral. São Paulo:Atlas, 2003. 